\title{
Transmitting Mediterranean food culture through art: a creative interdisciplinary approach
}

\author{
Sandro Dernini* \\ Forum on Mediterranean Food Cultures, Via Giovanni da Castelbolognese 89, 00153 Rome, Italy
}

Submitted 4 April 2006: Accepted 24 November 2006

\begin{abstract}
Objective: As a qualitative problem solving method, to manage the accelerating phenomenon of overweight and obesity among children and adolescents as well as to promote the Mediterranean Diet and the diversity of the Mediterranean Food Cultures heritage, it is presented a creative interdisciplinary approach through art.

Design: Taking into account that young generations are becoming the highest majority of the consumer population in the Southern and Eastern Mediterranean countries, it is reported the artist practice and the creative community-based interdisciplinary experience of Plexus International, a network of artists and scientists of various nationalities and disciplines.

Setting: Mediterranean Region and International.

Subject: Young Populations.

Results: Through the Ark of the Well Being project, artists and scientists have collaborate together, promoting The 2005 Rome Call for a Common Action in the Mediterranean and raising more attention on the erosion of the cognitive capacities of young generations by hunger and malnutrition.

Conclusions: A creative interdisciplinary approach was developed to transmit through art Mediterranean food culture with the aim to achieve a broader nutritional well being.
\end{abstract}

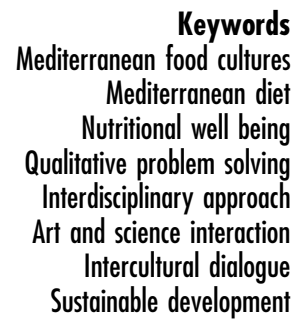

\section{Food security and nutritional well being in the Mediterranean}

The Forum on Mediterranean Food Cultures has the aim to advance the achievement of a broader nutritional well being and food security in the entire Mediterranean area, towards an effective sustainable development in the whole Mediterranean region.

The Forum, as an open framework, is fostering an interdisciplinary dialogue to fully acknowledge the underestimated role of the Mediterranean diet in preserving the diversity of the Mediterranean food cultures.

The initiative of the Forum started in 2002 in Calabria, Italy, coming from the experience of a series of international Well Being Reconciliation symposia, held in the 1990s, in Sardinia, with the technical collaboration of the FAO Food and Nutrition Division, focused on the human right of the nutritional well being for all.

\section{A challenge for the Mediterranean diet}

The artistic and creative process as an interdisciplinary qualitative problem-solving approach ${ }^{1}$ is proposed for the future actions of the Forum on Food Cultures to manage the accelerating phenomenon of overweight and obesity among children and adolescents ${ }^{2}$, as well as to deal with the increasing erosion of the Mediterranean food cultures heritage and of the traditional Mediterranean diet, under the risk of becoming an 'endangered species', as stressed since 1995 by Marion Nestle ${ }^{3}$.

Young generations in the Southern and Eastern Mediterranean countries are becoming the highest majority of the consumer population. Therefore, the creative art process as a qualitative problem solving should be more investigated and applied in such challenging undertaking.

More than before, in direction of the creation in 2010 of the Euro-Mediterranean free trade area, there is a need to define alternative strategies to preserve and to promote the diversity of the Mediterranean healthful dietary patterns through the uniformity of the globalisation.

\section{A change of route}

The creative interdisciplinary process of the interaction between science and art may facilitate the building of alternatives forms of dialogue among all Mediterranean regions for mobilising more resources to attain a necessary 'change of route' in the food consumers' patterns.

As it was pointed out by Jonas Salk: 'how long could we keep the epistemology of science and the epistemology of human experience apart without jeopardising our future 
through failing to realise the importance of science and art have for each other? ${ }^{4}$, we need to bring together artists and scientists of various disciplines and cultures to interact with each other to bridge the gap between the community and the academy, to collaborate together for a better understanding of different people and different living conditions within their respective communities.

It is important to integrate educational projects for preadolescents with interdisciplinary and multicultural approaches, in which art should have a significant role, by strengthening underlying and unifying elements and by ensuring an effective communication ${ }^{5}$.

With growing appreciation of the cultural identity of others, one gains the sense of respect that is so critical in living together with the diversity, and at the same time begins to acknowledge a new global vision of well being.

As stated in the WHO's constitution: 'Health is a state of complete physical, mental and social well-being and not merely the absence of disease or infirmity', and any formulation of a comprehensive vision of well being, as an expression of a healthy quality of life, should also include the cultural and aesthetic dimensions of the life in which we live.

\section{The Ark of the Well Being: a creative interdisciplinary project}

'The Ark of the Well Being' is an ongoing creative interdisciplinary art and science travelling project, made by Plexus International, a non-structured communitybased network of participants of various disciplines and nationalities ${ }^{6}$.

Plexus International has conceptualised and produced numerous cross-cultural art-science experimental events across Europe, Africa, Australia and North America, linking 'art' and 'food' as community sustainable development resources - to the achievement of the 'well-being'-as a human right for all people.

The Well Being Ark project originated in Sardinia, in 1995, on the occasion of the Second International Well Being Reconciliation Symposium 'Navigating Global Cultures: Strategies for the Well Being in the XXI Century', held at the University of Cagliari.

In 1996, the project was presented in Rome, at the event 'Eating Art/Get the Best from Your Food/Food for All', held on the occasion of the FAO World Food Summit.

In 2005, at the University of Rome 'La Sapienza', the project was presented on the occasion of the third EuroMediterranean Forum on Food Cultures, as a creative contribution made in collaboration with the National Academy of Dance to the recommendation by the European Commission for a common action on diet, physical activity and health.

The third Forum, by taking into consideration the need to reach a broader consensus on the definition of the Mediterranean $\operatorname{diet}^{7}$, accomplished the task to issue 'The
2005 Rome Call for a Common Action in the Mediterranean' to further implemented and promoted internationally.

\section{The 2005 Rome call for a common action in the Mediterranean}

The Call, by stressing the pivotal role of 'food' in the economic, social and cultural sustainable development of the Euro-Mediterranean partnership, acknowledged 'food' as a 'total social fact' to be more accounted in the intercultural and interreligious dialogue in the Mediterranean. It was underlined the identity of food as a vehicle for learning about diversity and transmitting knowledge of the other and increasing mutual understanding and social cohesion.

The Call fully acknowledged also the right for everybody to eat according to their own beliefs.

In the Call, the meaning of the ancient Greek word 'diaita' as equilibrium as lifestyle was stressed to consider the Mediterranean diet more than just a 'diet', but as a whole lifestyle pattern and a consensus position on an updated definition of the Mediterranean diet was outlined, to be further implemented.

The Call recommended to reinforce the attention towards the young generations and to the evolution of their Mediterranean style of life, as well as to sustain the creative process of the interaction of science, art and technology.

It was also recommended to launch in the Mediterranean a food culture 're-education' project for an effective action in the schools and to develop a thematic interdisciplinary network on 'Agriculture, Food and Culture', with a joint 'portal' website, to share experiences, researches and data.

The Call stressed the need to act together to revitalise local capacities towards the increasing erosion of the diversity of Mediterranean food cultures heritage.

On the occasion of the travelling art event 'Erosions and Renaissance Show' by Plexus International, the Call was promoted on board The Ark of the Well Being, in New York, on 10 December 2005, Human Rights Day, and after in Barcelona, on 8 March 2006, at the VI International Congress on the Mediterranean diet.

The Plexus International travelling event had the aim to raise more attention on the erosion around the world of the cognitive capacities of our young generations by hunger and malnutrition.

\section{Conclusions}

The metaphors of art may reinforce the cognitive process and can play an important role in categorising emotional memory and in structuring and recontextualising experience and in generating new meanings ${ }^{8}$. The increase of 
the use of metaphors in art and science may allow to bring more energies, cultures, disciplines and people together.

It is very hard to establish collaborations between scientists and artists as well as to develop effective interdisciplinary collaborations among scientists of different disciplines. Specialised and applied researches are bringing an accelerating fragmentation of the knowledge and increasing separations.

A new reinforced alliance between science and art will let the development of alternative strategies to deal with the challenging emergency of the overweight and obesity trend and of the growing erosion of the Mediterranean diet as well as of the Mediterranean food cultural heritage.

In conclusion, the Mediterranean complexity with its interdependent issues and the ongoing radical transformation of the contemporary global scenario urges a new qualitative problem solving. The creative interdisciplinary process of the interaction between art and science should be taken into more consideration in building alternative forms of dialogues between all Mediterranean stockholders to achieve a broader food security and nutritional well being in the entire Mediterranean region, within an effective participatory sustainable development effort.

\section{References}

1 Ecker D. The artistic process as qualitative problem solving. Journal of Aesthetics and Art Criticism 1963; 21: 283-90.

2 Commission of the European Communities. Green paper. Promoting Healthy Diets and Physical Activity: A European Dimension for the Prevention of Overweight, Obesity and Chronic Diseases COM 637. Bruxelles: EC, 2005.

3 Nestle M, ed. Mediterranean diets: historical and research overview. American Journal of Clinical Nutrition. 1995; 61(Suppl): 1313 S-1320S.

4 Salk J. The next evolutionary step in the ascent of man in the cosmos. Leonardo 1985; 18: 228.

5 Churchill A. Art for Preadolescents. New York: McGraw-Hill, 1970.

6 Dernini S. A Multicultural Aesthetic Inquiry Into 'Plexus Black Box', An International Community-Based Art Project. PhD. Dissertation, New York University, New York, 1997.

7 Serra-Majem L, Trichopoulou A, Ngo de la Cruz J, Cervera P, García-Álvarez A, La Vecchia C, Lemtouni A, Trichopoulous D. Does the definition of the Mediterranean diet need to be updated? Public Health Nutrition, 2004; 7(7): 927-9.

8 Eldelman $\mathrm{G}$. The wordless metaphor: visual art and the brain. In: Kertess K, ed. 1995-Biennial Exhibition. New York: Whitney Museum of American Art, 1995; 33-47. 